«La vie dans le monde. Perspectives chrétiennes et influences musulmanes. Une étude du Memrō II de l' Ethicon de Grégoire Abū l-Farağ Barhebraeus ", in : D. Aigle, éd., Barhebraeus et la renaissance syriaque (Actes du colloque, Collège de France, décembre 2007). Parole de l'Orient, vol. 33, 2008, p. 115-128.

\title{
Françoise Briquel-Chatonnet
}

\section{(2) OpenEdition \\ Journals}

\section{Édition électronique}

URL : http://journals.openedition.org/abstractairanica/39683

DOI : 10.4000/abstractairanica.39683

ISSN : 1961-960X

Éditeur :

CNRS (UMR 7528 Mondes iraniens et indiens), Éditions de l'IFRI

Édition imprimée

Date de publication : 15 mai 2011

ISSN : 0240-8910

\section{Référence électronique}

Françoise Briquel-Chatonnet, « «La vie dans le monde. Perspectives chrétiennes et influences musulmanes. Une étude du Memrō // de l'Ethicon de Grégoire Abū I-Faraǧ Barhebraeus », in : D. Aigle, éd., Barhebraeus et la renaissance syriaque (Actes du colloque, Collège de France, décembre 2007). Parole de l'Orient, vol. 33, 2008, p. 115-128. », Abstracta Iranica [En ligne], Volume 31 | 2011, document 225, mis en ligne le 11 octobre 2012, consulté le 05 octobre 2020. URL : http:// journals.openedition.org/abstractairanica/39683; DOI : https://doi.org/10.4000/abstractairanica. 39683

Ce document a été généré automatiquement le 5 octobre 2020.

Tous droits réservés 
« La vie dans le monde. Perspectives chrétiennes et influences musulmanes. Une étude du Memrō II de l'Ethicon de Grégoire Abū l-Farağ Barhebraeus ", in : D. Aigle, éd., Barhebraeus et la renaissance syriaque (Actes du colloque, Collège de France, décembre 2007). Parole de l'Orient, vol. 33, 2008, p. 115-128.

Françoise Briquel-Chatonnet

H. Teule souligne l'originalité du Memrō II de l'Ethicon de Bar Hebraeus, composé en 1279 à Marāga, dans lequel le savant abandonne le terrain théorique et spéculatif de ses autres écrits pour composer un traité pratique de direction spirituelle destiné à aider le chrétien à cheminer vers Dieu par les différentes pratiques de la religion. A l'opposé de l'«Ethicon» de sa grande encyclopédie, Hềwat Hekmtā, ou du Livre de la Colombe, rédigés par le même auteur, il n'est pas ici seulement question des moines et solitaires, mais de tout chrétien laïc qui souhaite mener une vie conforme à son idéal religieux. Ce traité est directement inspiré du livre d'al-Ġazālì, Ihyā' 'ulūm al-Dīn, dont il suit fidèlement le plan, mais dont il n'est pas pourtant une simple traduction syriaque : dans certains cas, il se contente d'ajouter une confirmation tirée de la littérature syriaque ; dans d'autres cas, il s'écarte de son modèle pour adopter sur un point une vision plus conforme à la théologie chrétienne; il lui arrive aussi de suivre le point de vue d'un autre auteur musulman, tel Avicenne; enfin, un dernier cas de figure est celui où Bar Hebraeus 
adopte certaines idées ou pratiques étrangères à sa propre tradition. De fait, pour composer ce traité, il ne pouvait guère puiser à la tradition spirituelle syriaque, toute tournée vers la vie monastique. Sa source d'inspiration chrétienne est essentiellement la littérature canonique.

Denise Aigle

INDEX

Thèmes : 6.3. Autres religions

\section{AUTEURS}

FRANÇOISE BRIQUEL-CHATONNET

CNRS - Orient et Méditerranée - Paris 